\title{
Elective hernia surgery cancellation due to the COVID-19 pandemic
}

\author{
F. Köckerling ${ }^{1} \cdot$ D. Köckerling ${ }^{2} \cdot$ Ch. Schug-Pass ${ }^{1}$
}

Received: 13 July 2020 / Accepted: 23 July 2020 / Published online: 29 July 2020

○) Springer-Verlag France SAS, part of Springer Nature 2020

\section{Dear Editor,}

The novel disease COVID-19 caused by the severe acute respiratory syndrome corona virus 2 (SARS-CoV-2) was declared a pandemic by the World Health Organisation on the 11th March 2020 [1]. With exponential increase in case numbers, 770,000 persons globally were infected by SARSCoV-2 at the end of March 2020 [1]. It was thought that approximately $10 \%$ of COVID-19 patients progress to severe disease requiring admission to hospital and, if necessary, to critical care units [1]. Consequently, healthcare providers around the world prepared for the overwhelming influx of critically ill patients, leading many governments and international surgical associations to demand the temporary discontinuation of elective surgical interventions [2].

It is estimated that 28 million elective operations were cancelled during the peak 12 weeks of disruption caused by COVID-19, equalling $72.3 \%$ of all elective surgery [3].

In February to June 2019, the hernia registry Herniamed documented up to 7000 inguinal hernia, 1700 umbilical hernia and 1200 incisional hernia repairs per month (Figs. 1, $2,3)$. Of those, the proportion of emergency repairs was $2.5 \%$ for inguinal hernias and $5.9 \%$ for both umbilical and incisional hernias.
Following the mid-March announcement by the German government to halt elective surgical interventions, the number of hernia repairs registered by Herniamed during March 2020 had already decreased considerably (Figs. 1, 2, 3). The lowest case load was documented in April 2020, during which the number of hernia repairs was equivalent to around 25\% of those performed in February to June 2019. These numbers were validated by billing data from health insurance companies [4]. Interestingly, the number of emergency hernia repairs did not increase as expected, but rather showed a trend towards decreasing (Figs. 1, 2, 3), which was confirmed by other analyses [5].

With SARS-CoV-2 infections decreasing during May 2020, the restrictions imposed on elective surgery in German hospitals were lifted, resulting in a rebound in the number of elective hernia repairs (Figs. 1, 2, 3). However, despite normalisation of hospital policies in Germany, the case load of hernia repairs in June 2020 was still significantly lower compared to June 2019.

These data from the Herniamed registry confirm that more than $70 \%$ of all elective hernia repairs were not performed during the peak weeks of the COVID-19 pandemic, leading to no overall increase in the rate of emergency repairs, contrary to expectations.
F. Köckerling

ferdinand.koeckerling@vivantes.de

1 Department of Surgery and Centre for Minimally Invasive Surgery, Academic Teaching Hospital of Charité Medical School, Vivantes Hospital, Neue Bergstrasse 6, 13585 Berlin, Germany

2 Medical Sciences Division, University of Oxford, Oxford, UK 


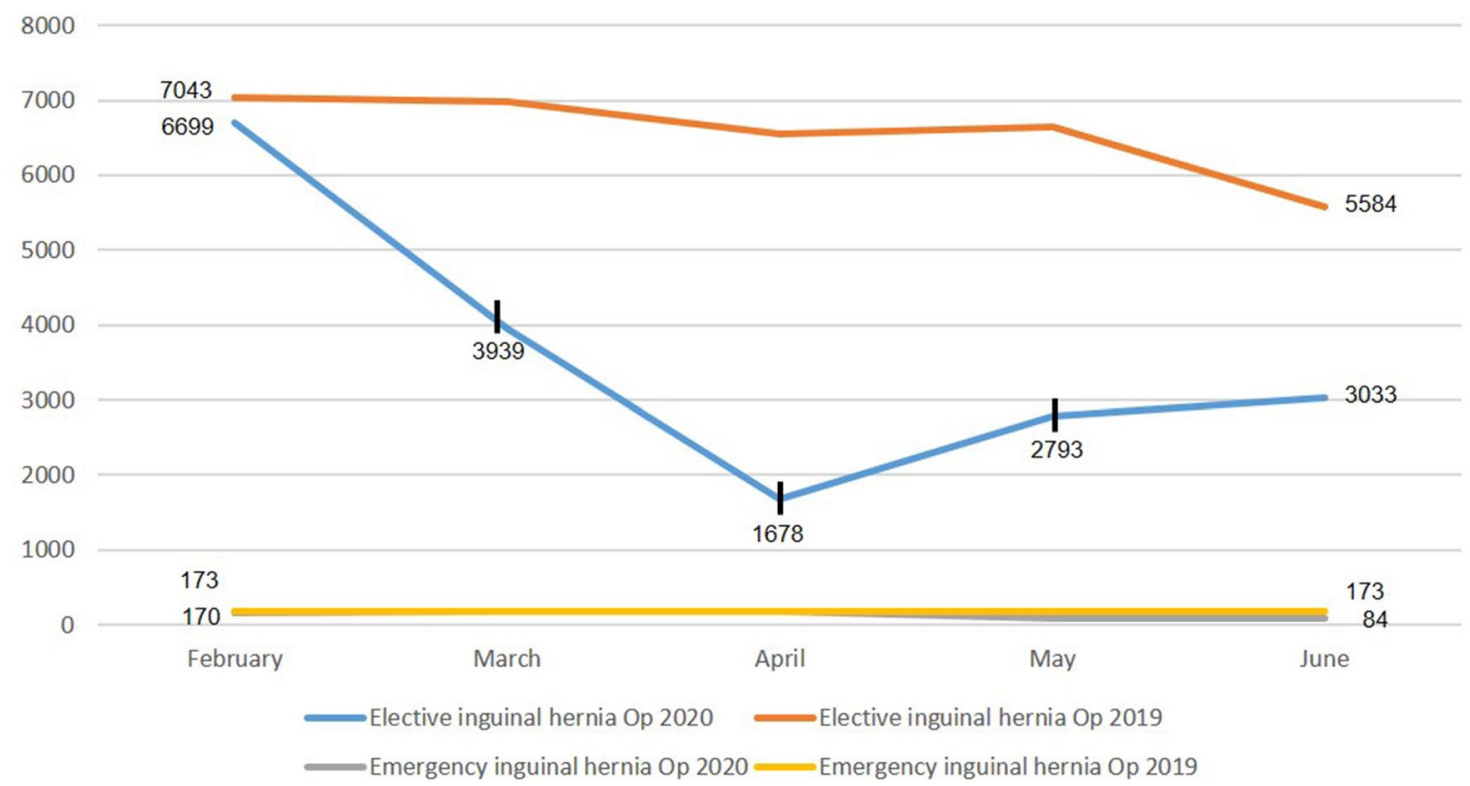

Fig. 1 Elective and emergency inguinal hernia operations documented in February-June 2020 vs. 2019 in the Herniamed registry

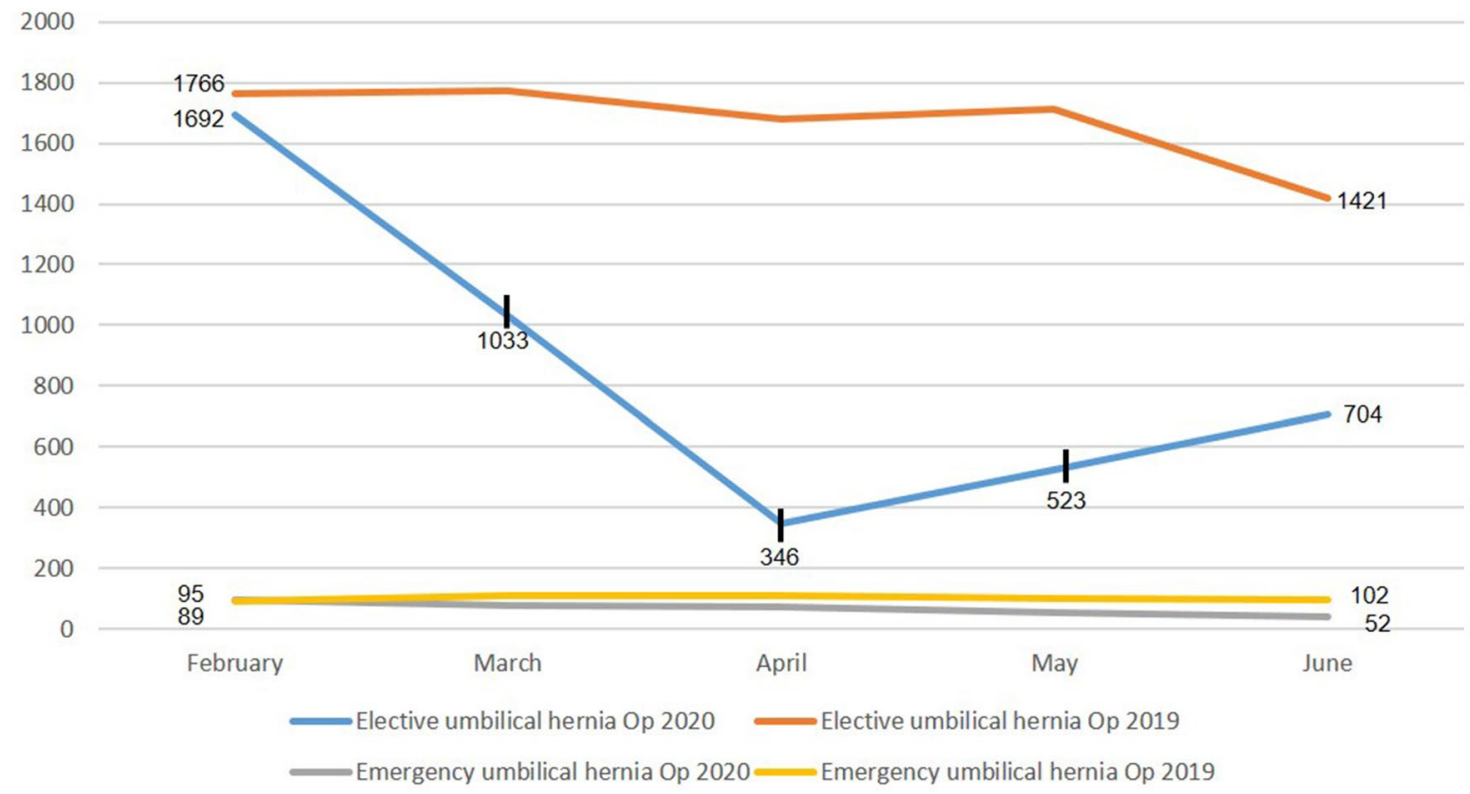

Fig. 2 Elective and emergency umbilical hernia operations documented in February-June 2020 vs. 2019 in the Herniamed registry 


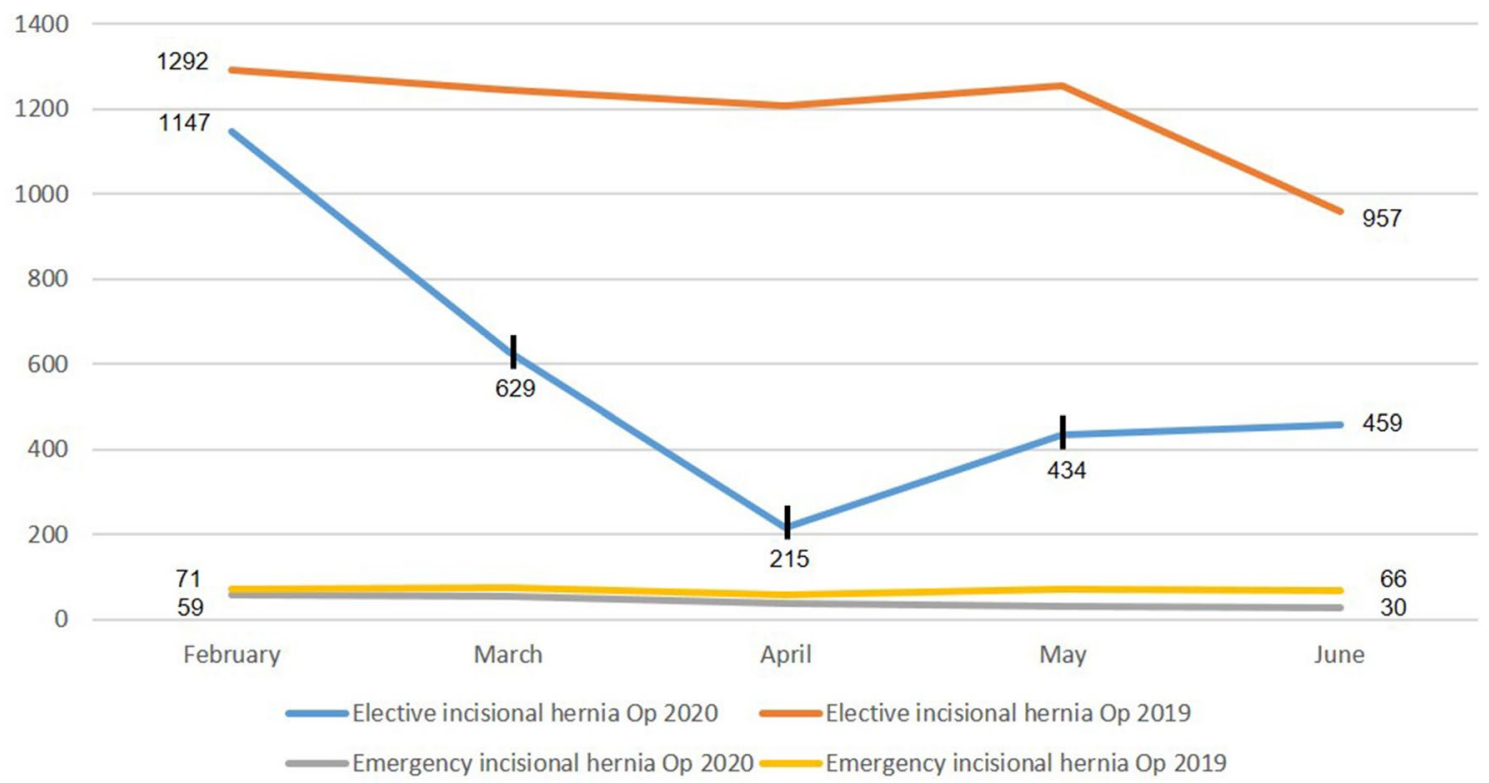

Fig. 3 Elective and emergency incisional hernia operations documented in February-June 2020 vs. 2019 in the Herniamed registry

\section{Compliance with ethical standards}

Conflict of interest Dr. Köckerling reports grants to fund Herniamed from Johnson \& Johnson, Norderstedt, Karl Storz, Tuttlingen, pfm medical, Cologne, Dahlhausen, Cologne, B Braun, Tuttlingen, MenkeMed, Munich, Bard, Karlsruhe. All other authors have nothing to disclose.

Ethical approval As only cases of routine hernia surgery are documented in the Herniamed Registry, an ethical approval was not neccessary.

Human and animal rights This article does not contain any study with animals performed by any of the authors.

Informed consent All patients with routine hernia surgery documented in the Herniamed Registry have signed an informed consent declaration agreeing to participate.

\section{References}

1. Blouhos K, Boulas KA, Paraskeva A, Triantafyllidis A, Nathanailidou M, Hatzipourganis K, Hatzigeorgiadis A (2020) Understandig surgical risk during COVID-19 pandemic: the rationale behind the decisions. Front Surg 7:33. https://doi.org/10.3389/ fsurg.2020.00033
2. Iacobucci G (2020) Covid-19: all non-urgent elective surgery is suspended for at least three months in England. BMJ 368:m1106. https://doi.org/10.1136/bmj.m1106

3. Nepogodiev D, Bhangu A, COVIDSurg Collaborative (2020) Elective surgery cancellations due to the COVID-19 pandemic: global predictive modelling to inform surgical recovery plans. $\mathrm{Br}$ J Surg. https://doi.org/10.1002/bjs.11746

4. Kuhlen R, Schmithausen D, Winklmair C, Schick J, Scriba P (2020) The effects of the COVID-19 pandemic and lockdown on routine hospital care for other illnesses. Dtsch Arztebl Int 117:488-489. https://doi.org/10.3238/arztebl.2020.0489

5. Lima DL, Pereira X, dos Santos DC, Camacho D, Malcher F (2020) Where are the hernias? A paradoxical decrease in emergency hernia surgery during COVID-19 pandemic. Hernia. https ://doi.org/10.1007/s10029-020-02250-2 (Online ahead of print)

Publisher's Note Springer Nature remains neutral with regard to jurisdictional claims in published maps and institutional affiliations. 